УДК 574:504.3.054:541.182.2

\title{
ЭЛЕМЕНТНЫЙ СОСТАВ ТВЕРДОЙ ФАЗЫ СНЕГОВОГО ПОКРОВА МАЛЫХ НАСЕЛЕННЫХ ПУНКТОВ (НА ПРИМЕРЕ СЕЛА ДОЛОНЬ ВОСТОЧНО-КАЗАХСТАНСКОЙ ОБЛАСТИ, РЕСПУБЛИКА КАЗАХСТАН)
}

Темиржанова Арай Ермековна', temirzhanova.aray@mail.ru

Дюсембаева Мадина Талгатовна 1 , koigeldinova@nnc.kz

Лукашенко Сергей Николаевич², lukashenko.1962@mail.ru

Язиков Егор Григорьевич 3 , yazikoveg@tpu.ru

Шакенов Ербол Зейнелгазинович", shakenov@nnc.kz

1 Национальный ядерный центр Республики Казахстан, Казахстан, 071100, г. Курчатов, ул. Бейбіт Атом, 2.

2 Всероссийский научно-исследовательский институт радиологии и агроэкологии, Россия, 249032, г. Обнинск, Киевское шоссе, 109 км.

3 Национальный исследовательский Томский политехнический университет, Россия, 634050, г. Томск, пр. Ленина, 30.

Актуальность данной работы обусловлена необходимостью расширения методов комплексных экологических исследований для оценки качества объектов окружающей среды малых населенных пунктов. Изучение элементного состава пылеаэрозольных выпадений даст наиболее полную картину о состоянии качества основных природных компонентов. Аэрозоли воздуха представляют собой сложную дисперсную систему, включающую в себя частицы размером менее 10 микрон. Эти частицы имеют как природное, так и техногенное происхождение: мелкодисперсные пылевые частицы почвы, растений, микроорганизмы, сажа, зола, составные части дымовых выбросов котельной, промышленности и т. д. Атмосфрерный воздух небольших населенных пунктов остается малоизученным, отсутствуют систематические данные о химическом составе атмоссрерных взвесей, в связи с чем и определяется актуальность данной работы.

Цель: определить элементный состав твердой фразы снегового покрова малого населенного пункта Долонь.

Объекты: пылеаэрозольные выпадения, твердые частицы аэрозолей воздуха, снеговой покров, уголь и зола.

Методы: масс-спектрометрический и атомно-эмиссионный с индуктивно-связанной плазмой.

Результаты. Изучен элементный состав снеготалой воды и твердой фазы снега. Для определения степени летучести химических элементов рассчитан их коэфрфициент обогащения из угля в золу. Определены основные зоны с повышенным содержанием тяжелых металлов в пылеаэрозольных выпадениях. В снеговом покрове исследуемой территории выявлена группа элементов с высокой миграционной способностью. Построены карты загрязнения снегового покрова населенного пункта Долонь с выделением участков (ореолов загрязнений) с повышенным содержанием исследуемых групп элементов.

Ключевые слова:

Пылеаэрозольные выпадения, снежный покров, твердый осадок снега, снеготалая вода, пылевая нагрузка, тяжелые металлы.

\section{Введение}

На сегодняшний день для оценки качества атмосферного воздуха крупных промышленных зон, а также населенных пунктов с наличием источников вредных выбросов широко применяют косвенные методы. К таковым методам относится снеговая съемка для определения наличия и концентраций загрязняющих веществ атмосферного воздуха [1-10]. Формирование химического состава снегового покрова происходит за счет переноса и осаждения из окружающего воздуха твердых пылевых частиц техногенного и природного происхождения, растворения осадками газообразных сложных компонентов. При этом следует отметить, что количество твердых частиц и взвешенных веществ в снеговом покрове характеризует запыленность территории и является одним из критериев степени загрязненности воздушного бассейна труднорастворимыми формами соединений и элементов [11-13]. Химический состав твердых частиц снегового покрова состоит преимущественно из элементов техногенного происхождения. Именно поэтому в настоящее время изучение элементного состава пылеаэрозольных выпадений, а также твердого осадка снега крупных и малых населенных пунктов по рекомендациям многих авторов представляет наибольший интерес с экологической точки зрения [14-21].

Впервые проведено комплексное исследование элементного состава пылеаэрозольных выпадений 
снегового покрова малого населенного пункта с. Долонь, расположенного на юго-западе Бескарагайского района Восточно-Казахстанской области Республики Казахстан вдоль ленточного бора Иртышского бассейна. Населенный пункт является административным центром Долоньского сельского округа, где 80 \% местного населения в зимний период для отопления домов используют древесину (сосна, осина), остальные 20 \% - уголь с месторождения Каражыра.

\section{Объекты и методы исследования}

Уголь и зола. Отбор проб угля и золы провели в середине октября 2015 г. Навески пробы массой 0,2 г помещали в тефлоновый вкладыш, добавляли небольшими порциями 10 мл 7М $\mathrm{HNO}_{3}$ марки «ос.ч.». Кислотное разложение проб проводили в герметичных автоклавах в течение 2,5 часов при температуре $160 \pm 5{ }^{\circ} \mathrm{C}$. Объем кислотных вытяжек, полученных таким способом, доводили до 15 мл 7М $\mathrm{HNO}_{3}$ марки «ос.ч.».

Снеготалая вода и твердый осадок снега. Методом шурфа в конце марта - начале апреля 2015 г. отобрали 30 проб снега. Шурфы были заложены по всей площади исследуемой территории. Метод шурфа предполагает закладку площадки размером $100 \times 100$ см на всю мощность снежного покрова, за исключением 5 см слоя над почвой, глубина шурфа в среднем не превышает 50 см. Масса снеговой пробы, отобранной с каждой площадки, составила примерно 10 кг. Также была отобрана «фоновая» проба на расстоянии 1,2 км в северо-западном направлении от села (рис. 1).

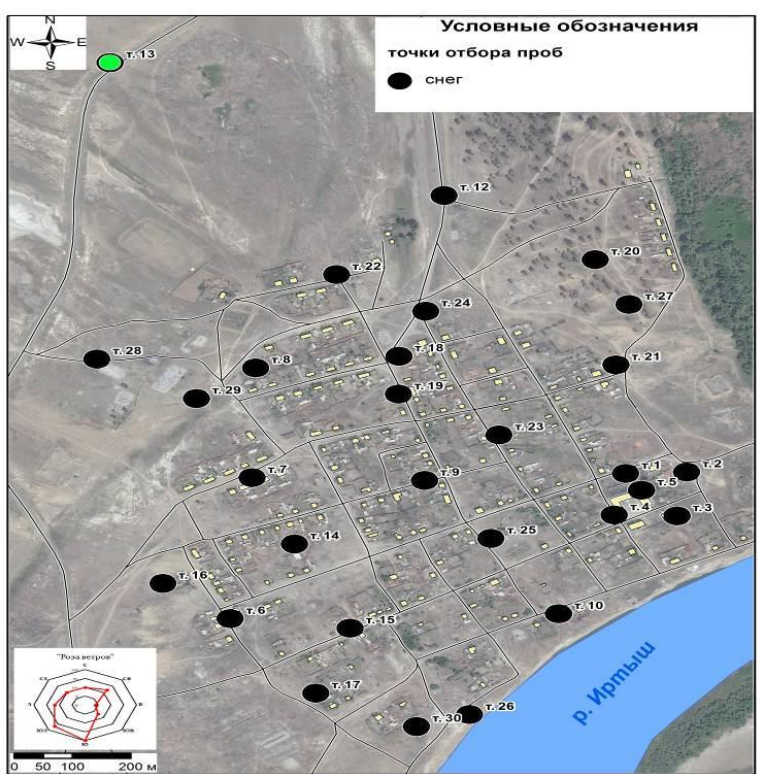

Pис. 1. Точки отбора проб

Fig. 1. Sampling points

Доставленные в лабораторию образцы снега размещали в глубокие емкости из пластмассы. В данных емкостях пробы оттаивали при комнатной температуре. После снеготалую воду отфуговывали для получения твердого осадка, и воду консервировали из расчета на 1 л воды 3 мл концентрированной азотной кислоты марки «ос.ч.» и передавали на анализ. Твердые частицы снега перекладывали в чистую тефлоновую емкость и высушивали до постоянной массы при комнатной температуре. Высушенные образцы твердых частиц снега разлагали способом автоклавной минерализации с использованием концентрированных фтористоводородной $(\mathrm{HF})$ и азотной $\left(\mathrm{HNO}_{3}\right)$ кислот в соотношении 1:2. Автоклавы выдерживали в сушильном шкафу в течение 4 ч, нагретом до температуры $160 \pm 5{ }^{\circ} \mathrm{C}$, приливали $7 \mathrm{M}$ азотную кислоту и выпаривали раствор до образования сухих солей при температуре $+160 \pm 5,0^{\circ} \mathrm{C}$. После охлаждения объем раствора доводили до 15 мл $7 \mathrm{M} \mathrm{HNO}_{3}$.

Определение содержания химических элементов в анализируемых образцах проводили методами МС-ИСП с использованием квадрупольного масс-спектрометра Agilent 7700x «Agilent Technologies» [22], а также АЭС-ИСП на приборе iCAP 6300 Duo «Thermo Scientific». Приготовили калибровочные растворы для построения градуировочных кривых из сертифицированных мультиэлементных стандартных образцов IV-ICPMS-71A, № 9300233, № 9300235, производства США, компании «Perkin Elmer». Относительное стандартное отклонение (RSD - relative standard deviation) измерений было меньше $10 \%$. Внутренний контроль качества измерений в лаборатории осуществляли путём измерения контрольного раствора (QC - quality control) c аттестованным содержанием исследуемых элементов через каждые 10 проб. Также для контроля воспроизводимости результатов во время анализа использовали контрольные (параллельные) образцы через каждые 15 проб. Эти процедуры применяются для выявления неопределенностей процесса пробоподготовки для элементного анализа. При неудовлетворительном результате применяемых методов контроля качества (отклонение калибровочного графика на 8 $10 \%$, отклонение контроля точности и показателей параллельных образцов от аттестованных значений на 20 \%) заново строили градуировочную кривую для исследуемых элементов. Анализ проб проводили на определение таких элементов, как $\mathrm{Be}, \mathrm{Mg}, \mathrm{V}, \mathrm{Cr}, \mathrm{Mn}$, $\mathrm{Fe}, \mathrm{Co}, \mathrm{Ni}, \mathrm{Cu}, \mathrm{Zn}, \mathrm{Ga}, \mathrm{Ge}, \mathrm{As}, \mathrm{Rb}, \mathrm{Sr}, \mathrm{Mo}, \mathrm{Cd}$, La, Ce, $\mathrm{Pr}, \mathrm{Nd}, \mathrm{Sm}, \mathrm{Pb}, \mathrm{Th}, \mathrm{U}$, по методике ISO 17294-2:2003 (E) c номером государственной регистрации $022 / 10505$ от 27.12 .2005 г.

Для того чтобы соотнести исследуемые компоненты в пробах угля с определенным классом по степени летучести и обогащаемости в золе рассчитали коэффициент обогащения $\left(\mathrm{K}^{0}\right)$ элементов, вычисляемый по формуле (1):

$$
\mathrm{K}^{0}=\mathrm{C}_{3} / \mathrm{C}_{\mathrm{y}},
$$

где $\mathrm{C}_{3}$ - содержание исследуемого элемента в золе, мг/кг; $\mathrm{C}_{\mathrm{y}}$ - содержание исследуемого элемента в угле, $\mathrm{M \Gamma} / \mathrm{Kг}$.

Количество пылеаэрозольных выпадений, экспонированных непосредственного в снегу, определяли с помощью показателя пылевой нагрузки (Pn) [23] как критерий загрязнения на единицу площади за определенный период (2): 


$$
\mathrm{Pn}=\mathrm{Po} /(\mathrm{S} \times \mathrm{t}),
$$

где Ро - масса пыли в пробе, мг; S - площадь шурфа, $\mathrm{M}^{2} ; \mathrm{t}$ - время от начала снегостава до отбора пробы, сутки.

Также рассчитали показатель баланса между наличием химических элементов в составе твердой фазы и снеготалой воды снегового покрова [23, 24]. Долю в процентах содержания химического элемента, относящуюся к твердой фазе снега (Дтос), рассчитывали согласно формулам (3.1-3.4):

$$
\begin{aligned}
& \text { Д }_{\text {TOC }}=\left(\mathrm{Pi}_{\text {TOC }} \times 100\right) / \mathrm{Pi}_{\text {снег }} \text {, } \\
& \mathrm{Pi}_{\text {снег }}=\mathrm{Pi}_{\text {тос }}+\mathrm{Pi}_{\text {снеготалая вода, }} \\
& \mathrm{Pi}_{\text {TOC }}=(\mathrm{C} \mathrm{M \Gamma} / \mathrm{K \Gamma} \times \mathrm{P}) / 1000 \text {, } \\
& \mathrm{Pi}_{\text {снеготалая вода }}=\mathrm{Ci}_{\text {снеготалая вода }} \times \mathrm{V} \text {, }
\end{aligned}
$$

где $\mathrm{Pi}_{\text {тос }}$ - масса химического элемента в составе твердой фазы снега, мг; $\mathrm{Pi}_{\text {снег }}$ - масса химического элемента в составе снеговой пробы в целом, мг; $\mathrm{Pi}_{\text {сне- }}$ готалая вода - масса химического элемента в составе снеготалой воды, мг; С - концентрация химического элемента в твердой фазе снега, мг/кг; Р - масса пыли в пробе снега, г; $\mathrm{Ci}_{\text {снеготалая вода }}-$ концентрация химического элемента в снеготалой воде, мг/дм³ $; \mathrm{V}$ - объем растворимой фазы снега, полученный после таяния снеговой пробы, дм ${ }^{3}$.

Процентную долю содержания химического элемента, приходящуюся на снеготалую фазу снега (Д сне-

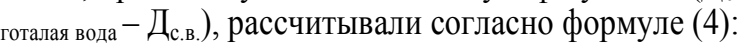

$$
\text { Д снеготалая вода }=100-Д_{\text {тос. }}
$$

\section{Обсуждение результатов}

Снег. Для изучения динамики содержания и пространственного распределения химических элементов в снеговом покрове исследуемой территории определены их концентрации водорастворимых и труднорастворимых форм. Среднее содержание и пределы колебаний химических элементов в жидкой и твердой фазах снегового покрова представлены в табл. 1.

Концентрация элементов в снеготалой воде варьирует от 0,0005 до 280 мкг/л. Также в жидкой фазе снега фоновой пробы определены значения концентрации химических элементов меньше предела обнаружения прибора. На сегодняшний день отсутствуют показатели допустимых уровней содержания химических элементов в снежном покрове. Поэтому для оценки предельно допустимых концентраций химических элементов в снежном покрове современные авторы используют фоновый подход. В данном случае в качестве основного значения принято считать содержание $i$-го элемента в снежном покрове относительно его концентрации в снеге, отобранном с фоновой территории. При этом данный участок характеризуется однородностью ландшафта и неподверженностью техногенному воздействию $[25,26]$. По такому же принципу содержание химических элементов в составе снега малых населенных пунктов сравнили с их концентрациями в снегу, отобранном с фонового участка.

В нашем исследовании при анализе состояния фонового участка выявлено относительно высокое содержание галлия и урана в твердой фазе снежного покрова, в сравнении с другими элементами, концентрация которых составила меньше предела обнаружения прибора. Это, вероятно, связано с переносом твердых частиц аэрозолей воздуха диаметром менее 2,5 микрон, которые содержатся в составе сажи, пыли, зольного остатка, на дальние расстояния и метеоусловиями регионального климата. Следует отметить, что содержание исследуемых химических элементов в снеготалой воде не превышает их предельно допустимые концентрации (ПДК) в питьевой воде, указанные в санитарно-эпидемиологических требованиях.

\begin{tabular}{|c|c|c|c|c|}
\hline \multirow[b]{2}{*}{$\begin{array}{c}\text { Эле- } \\
\text { мент } \\
\text { Element }\end{array}$} & \multicolumn{2}{|c|}{$\begin{array}{c}\text { Снеготалая вода } \\
\text { Melted snow }\end{array}$} & \multicolumn{2}{|c|}{$\begin{array}{l}\text { Твердый осадок снега } \\
\text { Solid snow deposition }\end{array}$} \\
\hline & $\begin{array}{c}\text { мкг/л } \\
\mu \mathrm{g} / 1\end{array}$ & $\begin{array}{c}\text { Фоновая } \\
\text { проба } \\
\text { Background } \\
\text { sample } \\
\end{array}$ & $\begin{array}{l}\mathrm{M \Gamma} / \mathrm{K \Gamma} \\
\mathrm{mg} / \mathrm{kg}\end{array}$ & $\begin{array}{c}\text { Фоновая } \\
\text { проба* } \\
\text { Background } \\
\text { sample* }\end{array}$ \\
\hline V & $\frac{1,0 \pm 0,2}{0,3-6,7}$ & $<0,05$ & $\frac{60 \pm 6,5}{14-170}$ & $<0,05$ \\
\hline $\mathrm{Cr}$ & $\frac{0,20 \pm 0,03}{0,03-0,6}$ & $<0,01$ & $\frac{60 \pm 9,1}{4-240}$ & $<0,01$ \\
\hline $\mathrm{Mn}$ & $\frac{12 \pm 3}{0,2-88}$ & $<0,1$ & $\underline{380 \pm 46}$ & $<0,1$ \\
\hline $\mathrm{Fe}$ & $\frac{50 \pm 14}{6-280}$ & $<0,5$ & $\frac{22000 \pm 2500}{5300-61000}$ & $310 \pm 6$ \\
\hline Co & $\begin{array}{l}0,20 \pm 0,01 \\
0,020-1,6\end{array}$ & $<0,01$ & $\frac{12 \pm 1,4}{2,2-34}$ & $<0,01$ \\
\hline $\mathrm{Ni}$ & $\frac{0,50 \pm 0,10}{0,020-2,40}$ & $<0,01$ & $\frac{38 \pm 5,0}{3-120}$ & $<0,01$ \\
\hline $\mathrm{Cu}$ & $\frac{1,3 \pm 0,3}{0,4-10}$ & $<0,1$ & $\frac{140 \pm 58}{2-1700}$ & $<0,1$ \\
\hline $\mathrm{Zn}$ & $\begin{array}{l}1,3 \pm 0,1 \\
0,2-170\end{array}$ & $<0,1$ & $\frac{430 \pm 120}{7-3500}$ & $<0,2$ \\
\hline $\mathrm{Ga}$ & $\frac{2,0 \pm 0,2}{0,7-6,8}$ & $<0,1$ & $\frac{46 \pm 6,1}{5,0-130}$ & $0,4 \pm 0,1$ \\
\hline As & $\frac{1,0 \pm 0,1}{0,4-3,5}$ & $<0,1$ & $\frac{24 \pm 5,1}{3-130}$ & $<0,25$ \\
\hline $\mathrm{Sr}$ & $\frac{18 \pm 3,4}{4,1-95}$ & $<0,1$ & $\frac{150 \pm 25}{17-580}$ & $<0,1$ \\
\hline $\mathrm{Cd}$ & $\frac{0,07 \pm 0,01}{0,005-0,40}$ & $<0,001$ & $\frac{4,4 \pm 1,1}{0,2-23}$ & $<0,001$ \\
\hline $\mathrm{La}$ & $\frac{0,030 \pm 0,001}{0,004-0,2}$ & $<0,001$ & $\frac{19 \pm 1,8}{6-46}$ & $<0,001$ \\
\hline $\mathrm{Ce}$ & $\frac{0,05 \pm 0,01}{0,007-0,4}$ & $<0,001$ & $\frac{40 \pm 4,0}{12-95}$ & $<0,001$ \\
\hline $\mathrm{Nd}$ & $\frac{0,02 \pm 0,01}{0,005-0,06}$ & $<0,001$ & $\frac{20 \pm 2,0}{6,1-48}$ & $<0,001$ \\
\hline $\mathrm{Sm}$ & $\frac{0,0005 \pm 0,0001}{0,0005-0,060}$ & $<0,0001$ & $\frac{4,7 \pm 0,7}{1,3-20}$ & $<0,0001$ \\
\hline $\mathrm{Pb}$ & $\frac{0,7 \pm 0,3}{0,06-7,2}$ & 0,10 & $\frac{120 \pm 18}{9-410}$ & $<0,1$ \\
\hline Th & $\frac{0,030 \pm 0,001}{0,003-0,3}$ & $<0,001$ & $\frac{4,0 \pm 0,4}{1,1-10}$ & $<0,001$ \\
\hline $\mathrm{U}$ & $\frac{0,030 \pm 0,004}{0,004-0,11}$ & $<0,001$ & $\frac{1,2 \pm 0,2}{0,3-4,3}$ & $0,04 \pm 0,01$ \\
\hline
\end{tabular}

Таблица 1. Среднее содержание и предель колебания химических элементов в снежном покрове $(n=30)$

Table 1. Average content and variation limits of chemical elements in the snow cover $(n=30)$

Примечание: $n$-количество проб, в числителе - среднее содержание и его ошибка, в знаменателе-минимальное и максимальное значение концентрачии; * - предель обнаружения прибора выражены в мкг/л.

Note: $n$-number of samples, in the nominator-the average content and uncertainty, in the denominator - minimum and maximum concentration value; * - instrument detection limits are expressed in $\mu \mathrm{g} / \mathrm{l}$. 

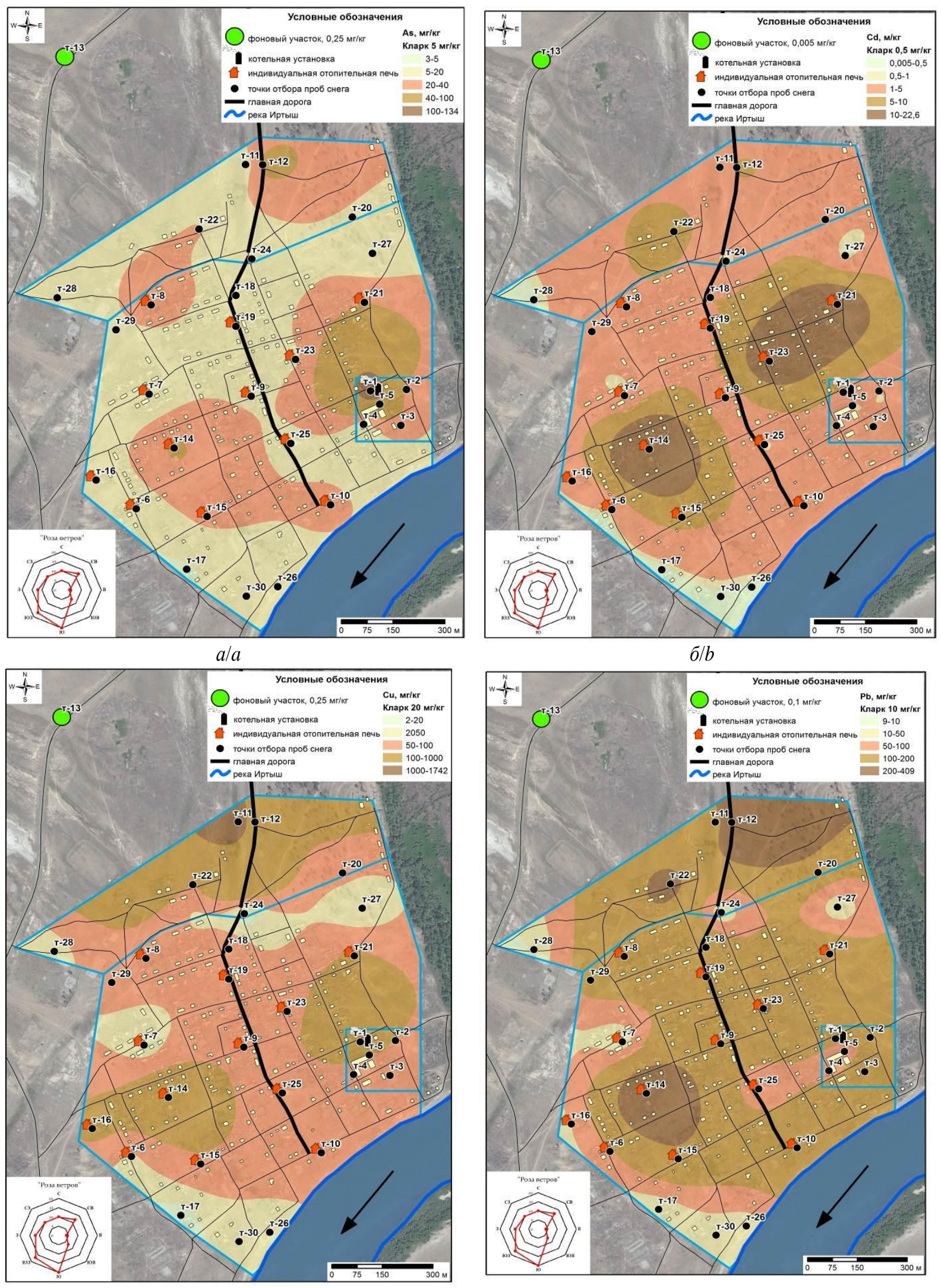

$B / c$

zld

Pис. 2. Распределение концентрации элементов в твердой фазе снегового покрова: мышьяка (а), кадмия (б), меди (в) и свиния (2)

Fig. 2. Distribution of elements concentration in the solid phase of the snow cover: arsenic (a), cadmium (b), copper (c) and lead $(d)$ 
Наибольший интерес представляет анализ содержания химических элементов в твердой фазе снегового покрова, поскольку в ней содержится основная часть элементов техногенного происхождения, выбрасываемых в слаборастворимой форме. Труднорастворимые формы исследуемых элементов определены с помощью выщелачивания минеральными кислотами твердого осадка снега способом автоклавного разложения. Содержание химических элементов в твердом осадке снега составляет от 0,04 до 61000 мг/кг. В твердом осадке снега с фонового участка выявлены концентрации железа, галлия и урана со следующим содержанием - 310; 0,4 и 0,04 (мг/кг).

Снег, отобранный на участках с постоянным антропогенным прессом, как показали исследования, содержит в своих труднорастворимых частицах концентрации элементов, в значительной мере превышающие содержание, установленное в пробах снега с фонового участка. Из всех изучаемых нами элементов наиболее высокие концентрации показали $\mathrm{As}, \mathrm{Cd}, \mathrm{Cu}$ и $\mathrm{Pb}$. С помощью картирования снегового покрова исследуемой территории определены «участки» распространения концентраций вышеперчисленных химических элементов и установлены зоны влияния источников их поступления (рис. 2, $a-2$ ).

По представленным данным в твердой фазе снега выявлена группа элементов, содержание которых превышает их ПДК в почве, утвержденные совместным приказом Министерства здравоохранения и Министерства охраны окружающей среды Республики

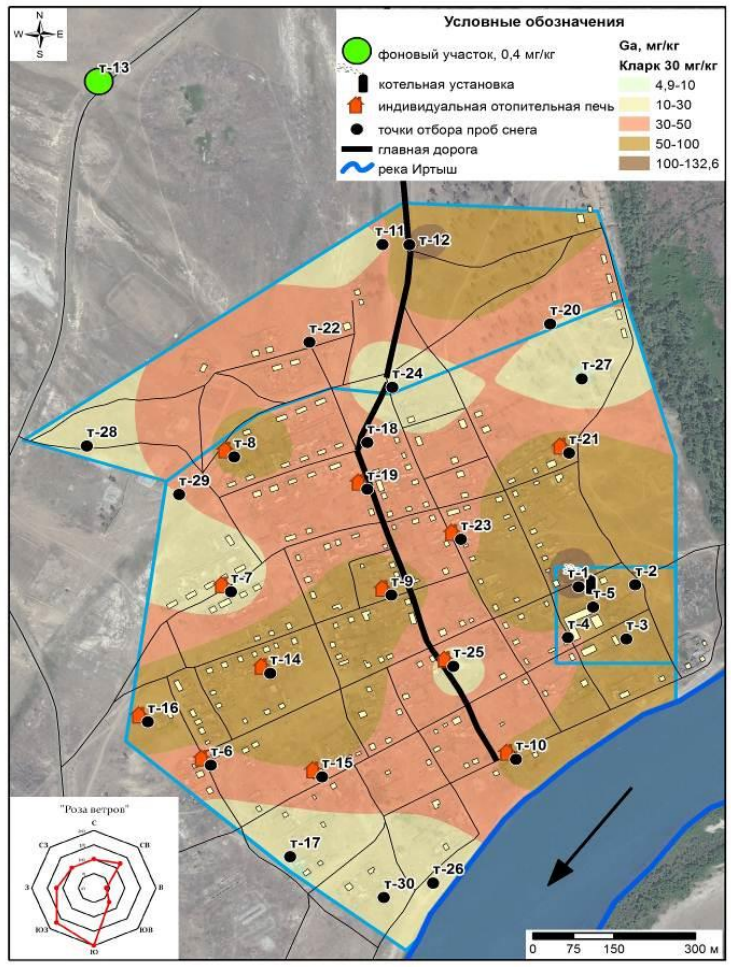

ala
Казахстан. К данной группе относятся: мышьяк, кадмий, медь и свинец.

Далее представлен убывающий ряд загрязнения снегового покрова исследуемой территории:

$$
\mathrm{As}_{12}>\mathrm{Cd}_{8,8}>\mathrm{Cu}_{4,2}>\mathrm{Pb}_{3,8} \text {. }
$$

Примечание: в индексе указана кратность превышения ПДК данных элементов в почве.

В снежном покрове содержание элементов определяется размещением и мощностью источников поступления элементов. Как видно из представленных карт, основным источником поступления мышьяка в снеговой покров является котельная, расположенная в юго-восточной части села. Также выявлены локальные участки загрязнения снежного покрова мышьяком, кадмием, медью и свинцом по всей площади села. Уровни накопления данных поллютантов в твердых частицах снега снижаются по мере удаления от их источников поступления. В частности, наблюдается снижение концентрации кадмия в твердом осадке снега по мере удаления от точек 21, 23, 14. Выявлено высокое содержание меди в пробе снега, отобранной с точки 11. Определено содержание свинца в твердом осадке снега, превышающее его ПДК в почве в точках 12, 22, которые расположены в непосредственной близости от транспортной дороги, а также в точках 14 23. Наблюдается тенденция распространения концентрации загрязняющих элементов по господствующему направлению ветра в отопительный сезон.

Также в пробах твердой фазы снега определено содержание галлия и цинка, превышающее их кларки в составе земной коры (рис. $3, a, \sigma)$.

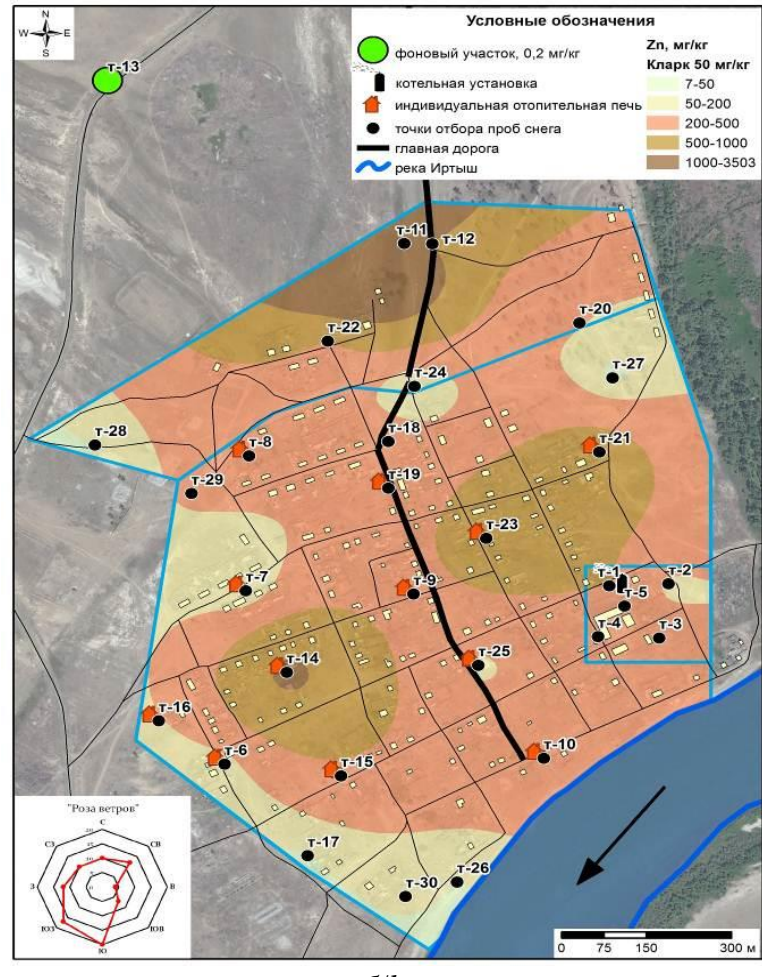

$6 / b$

Pис. 3. Распределение концентрации галлия (а) и цинка (б) в твердой фазе снегового покрова

Fig. 3. Distribution of gallium (a) and zinc (b) concentration in snow cover solid phase 
Как видно из представленных данных, среднее содержание галлия превышает его кларк в 2,4 раза, цинка в -5 раз соответственно.

Фоновая проба снега, отобранная на расстоянии 1,2 км в северо-западном направлении от села, характеризуется природными значениями содержания изученных элементов, не превышающими их средний состав в почве и земной коре.

Таким образом, при нормировании содержания тяжелых металлов в твердой фазе снега к их предельно допустимой концентрации в почве выявлены участки территории села Долонь с повешенным содержанием ряда тяжелых металлов, а именно мышьяка, кадмия, меди и свинца.

Для получения общей картины о концентрации элементов в снеговом покрове с. Долонь проведен расчет о долях содержания их в жидкой и твердой фазах. Доля растворенных форм нахождения химических элементов в пробах снега исследуемой территории относительно мала за исключением кадмия, галлия мышьяка и стронция. Для указанных элементов, характеризующихся высокой степенью подвижности, доля содержания растворённых форм нахождения преобладает над взвесью на 40-60 \%. По полученным данным можно предположить возможные изменения концентраций этих элементов в почве в зависимости от степени подвижности. Это может быть обусловлено интенсивным пылевым притоком из атмосферного воздуха (сжигание топлива), физико-химическими условиями среды и природой самих элементов.

Одним из критериев оценки состояния атмосферного воздуха в зимний пеиод является выявление среднесуточной пылевой нагрузки (Pn). В отопительный сезон величина среднесуточной Pn [27] на исследуемой территории изменяется от 5 до $450 \mathrm{Mr} /\left(\mathrm{M}^{2}\right.$ хсут.). По степени запыленности исследуемую территорию можно условно разделить на участки со средней и низкой степенями нагрузки в отопительный сезон. Так, участки возле котельной (т. 5), на пересечении транспортных дорог (т. 24), и на югозападе села (т. 17) характеризуются средней степенью пылевой нагрузки. Следует отметить, что для участка территории, который расположен в северо-восточной части села, выявлен наибольший показатель пылевого притока - $450 \mathrm{Mг} /\left(\mathrm{M}^{2}\right.$ хсут.) [23].

Уголь и зола. Одним из косвенных показателей содержания в атмосферном воздухе химических элементов, в том числе тяжелых металлов, являются данные по выбросам твердых веществ (сжигание органического топлива). Снеговой покров, как уже было отмечено выше, является депонирующей средой для выбросов всех промышленных объектов, в том числе отопительных систем (котельная), которые содержат нормируемые и ненормируемые компоненты. Твердые частицы от вышеуказанных источников накапливаются в снегу за период с ноября (образование устойчивого снегового покрова) до конца марта (начало снеготаяния).

Среднее содержание химических элементов в пробах угля и золы исследуемого населенного пункта представлено в табл. 2.
Таблица 2. Среднее содержание и пределы колебания химических элементов в образцах угля и золь, используемых в с. Долонь мг/кг $(n=10)$

Table 2. Average content and variation limits of chemical elements in coal and ash samples for Dolon village, $\mathrm{mg} / \mathrm{kg}(\mathrm{n=10})$

\begin{tabular}{|c|c|c|c|}
\hline $\begin{array}{l}\text { Элемент } \\
\text { Element }\end{array}$ & $\begin{array}{c}\text { Уголь } \\
\text { Coal }\end{array}$ & $\begin{array}{l}\text { Зола } \\
\text { Ash }\end{array}$ & $\begin{array}{l}{ }^{*} \mathrm{~K}^{0} \\
{ }^{*} \mathrm{E}^{\mathrm{f}}\end{array}$ \\
\hline $\mathrm{Be}$ & $\frac{0,43 \pm 0,02}{0,40-0,50}$ & $\frac{1,6 \pm 0,1}{1,3-1,8}$ & 3,7 \\
\hline $\mathrm{Mg}$ & $\frac{580 \pm 7}{570-610}$ & $\frac{2100 \pm 120}{1600-2300}$ & 3,6 \\
\hline V & $\underline{40 \pm 1}$ & $\frac{150 \pm 8}{120-170}$ & 3,5 \\
\hline $\mathrm{Cr}$ & $\frac{25 \pm 1}{22-30}$ & $\frac{75 \pm 4}{58-86}$ & 3,0 \\
\hline $\mathrm{Mn}$ & $\frac{94 \pm 7}{75-130}$ & $\frac{310 \pm 50}{150-490}$ & 3,3 \\
\hline $\mathrm{Fe}$ & $\frac{4500 \pm 420}{3700-6500}$ & $\frac{11000 \pm 860}{9700-12100}$ & 2,4 \\
\hline Co & $\frac{6,0 \pm 0,4}{5,0-8,0}$ & $\frac{23 \pm 2}{16-27}$ & 3,8 \\
\hline $\mathrm{Ni}$ & $\frac{17 \pm 1}{16-20}$ & $\frac{64 \pm 5}{46-78}$ & 3,8 \\
\hline $\mathrm{Cu}$ & $\frac{40 \pm 1}{33-42}$ & $\frac{180 \pm 15}{120-220}$ & 4,5 \\
\hline $\mathrm{Zn}$ & $\frac{50 \pm 4}{40-67}$ & $\frac{90 \pm 7}{70-120}$ & 1,8 \\
\hline $\mathrm{Ga}$ & $\frac{11 \pm 1}{9-13}$ & $\frac{38 \pm 3}{32-53}$ & 3,6 \\
\hline $\mathrm{Ge}$ & $\frac{1,3 \pm 0,1}{1,2-1,6}$ & $\frac{3,2 \pm 0,3}{2,0-4,0}$ & 2,3 \\
\hline As & $\frac{3,0 \pm 0,3}{2,0-4,0}$ & $\begin{array}{l}9,3 \pm 0,8 \\
7,0-11,0\end{array}$ & 3,0 \\
\hline $\mathrm{Rb}$ & $\frac{8,0 \pm 0,1}{8,0-8,0}$ & $\frac{22 \pm 1}{20-24}$ & 2,5 \\
\hline $\mathrm{Sr}$ & $\frac{160 \pm 8}{130-180}$ & $\frac{580 \pm 50}{400-750}$ & 3,8 \\
\hline Мo & $\frac{0,50 \pm 0,03}{0,50-0,60}$ & $\frac{1,4 \pm 0,2}{0,8-2,1}$ & 2,8 \\
\hline $\mathrm{La}$ & $\frac{6,6 \pm 0,3}{6,0-8,0}$ & $\frac{23 \pm 2}{15-29}$ & 3,3 \\
\hline $\mathrm{Ce}$ & $\frac{16 \pm 1}{13-18}$ & $\frac{58 \pm 5}{35-73}$ & 3,6 \\
\hline $\operatorname{Pr}$ & $\frac{2,0 \pm 0,1}{2,0-2,0}$ & $\frac{7,3 \pm 0,6}{5,0-9,0}$ & 3,7 \\
\hline $\mathrm{Nd}$ & $\frac{10 \pm 1}{9-12}$ & $\frac{35 \pm 3}{24-42}$ & 3,5 \\
\hline $\mathrm{Sm}$ & $\frac{2,0 \pm 0,2}{2,0-3,0}$ & $\frac{8,2 \pm 0,5}{6,0-9,0}$ & 4,1 \\
\hline $\mathrm{Pb}$ & $\frac{4,5 \pm 0,5}{3,1-6,5}$ & $\frac{15 \pm 0,7}{12-16}$ & 3,3 \\
\hline Th & $\frac{0,80 \pm 0,04}{0,60-0,90}$ & $\frac{2,8 \pm 0,2}{2,1-3,2}$ & 3,8 \\
\hline $\mathrm{U}$ & $\frac{0,20 \pm 0,01}{0,20-0,20}$ & $\underline{0,8 \pm 0,1}$ & 4,0 \\
\hline
\end{tabular}

Примечание: $n$ - количество проб, в числителе - среднее содержание и его ошибка, в знаменателе -минимальное и максимальное значение концентрации; ${ }^{\circ} K^{o}-$ коэффиициент обогащения.

Notice: $n$ - number of samples, in the numerator - the average content and uncertainty, in the denominator minimum and maximum concentration values; *Ef enrichment factor.

Как видно из таблицы, среднее значение коэффициента обогащения элементов для угля равно приблизительно 3,4. Если $\mathrm{K}^{0} \leq 3,4$, то при озолении угля элементы, подвергаемые температурному воздействию, больше переходят в газовую форму и истощаются в 
зольном остатке. При $\mathrm{K}^{0}>3,4$ элементы переходят больше в твердую фазу зольного остатка.

По данным таблицы значение коэффициента обогащения до 3,4 характерено для следующих элементов: $\mathrm{Cr}, \mathrm{Mn}, \mathrm{Fe}, \mathrm{Zn}, \mathrm{Ge}, \mathrm{As}, \mathrm{Rb}, \mathrm{Mo}, \mathrm{La}$ и $\mathrm{Pb}$. Возможно, в отопительный период поступление в атмосферу данных элементов-примесей при сгорании угля будет значительно, что частично подтверждено исследованиями по изучению элементного состава аэрозолей, а именно выявленными зимой высокими содержаниями мышьяка и молибдена [28, 29].

Поступление химических элементов в компоненты природной среды (вода, воздух, почва, снег) при сжигании угля происходит за счет распространения в составе летучей сажи на дальние расстояния и выпадения крупных частиц золы вблизи источника [30]. Возможно, элементы с $\mathrm{K}^{0}>3,4 \mathrm{Be}, \mathrm{Mg}, \mathrm{V}, \mathrm{Co}, \mathrm{Ni}, \mathrm{Cu}$, $\mathrm{Ga}, \mathrm{Sr}, \mathrm{Ce}, \mathrm{Pr}, \mathrm{Nd}, \mathrm{Sm}$, Th и U распространяются в составе летучей золы и в дальнейшем осаждаются на снеговой покров.

Поскольку утвержденные экологические нормативы содержания микроэлементов в угле и золе отсутствуют, при анализе полученных результатов были использованы кларки элементов-примесей в каменных углях и их золе [31]. В пробах угля обнаружены концентрации ванадия, хрома, меди, цинка, галлия и стронция, превышающие их кларки в 2 раза. Высокие содержания этих же элементов, за исключением ванадия, обнаружены в твердом осадке снега, т. е. в пылеаэрозольных выпадениях, что было отмечено выше. В исследуемых образцах золы содержание меди превышает его кларк в 2 раза и предельно допустимую

\section{СПИСОК ЛИТЕРАТУРЫ}

1. Snow spectral albedo at Summit, Greenland: measurements and numerical simulations based on physical and chemical properties of the snowpack / C.M. Carmagnola, F. Domine, M. Dumont, P. Wright, B. Strellis, M. Bergin, J. Dibb, G. Picard, Q. Libois, L. Arnaud, S. Morin // The Cryosphere. - 2013. - V. 7. - № 4. P. 1139-1160.

2. McNeill V.F. Atmospheric aerosols: clouds, chemistry, an climate // Annual review chemical and biomolecular engineering. - 2017. - V. 8. - P. 427-444. DOI: 10.1146/annurevchembioeng-060816-101538

3. Холодов А.С. Геоэкологическая оценка загрязнения атмосферы малых и средних населенных пунктов Приморского края микроразмерными частицами: дис. ... канд. географ. наук. Владивосток, 2019. - $184 \mathrm{c.}$

4. Аэрозоли Сибири / И.С. Андреева, А.Н. Анкилов, А.М. Бакланов, К.П. Куценогий. - Новосибирск: Изд-во СО РАН, 2006. $548 \mathrm{c}$.

5. Mołocznik A. Qualitative and quantitative analysis of agricultural dust in working environment // Annals of agricultural environmental medicine. - 2002. - V. 9. - № 1. - P. 71-78.

6. Spatial and temporal variations of six criteria air pollutants in 31 provincial capital cities in China during 2013-2014 / Y. Wang, Q. Ying, J. Hu, H. Zhang // Environment international. - 2014. V. 73. - P. 413-422. DOI: 10.1016/j.envint.2014.08.016.

7. Elik A. Monitoring of heavy metals in urban snow as indicator of atmosphere pollution // International Journal of Environmental Analytical Chemistry. - 2002. - V. 82. - № 1. - P. 37-45.

8. Кириллин А.Р., Макаров В.Н. Геохимия снежного покрова горных мерзлотных ландшафтов Эльконского ураново-рудного района // Наука и образование. - 2016. - № 4. - С. 64-69.

9. Исследования состояния снегового покрова Санкт-Петербурга Е.М. Нестеров, Л.М. Зарина, М.А. Маркова, И.В. Грачева, А.В. Воронцова, Ю.А. Макарова // Экологическая безопас- концентрацию в почве в 5 раз. В целом угли исследуемого месторождения с экологической точки зрения могут считаться нетоксичными. Однако в процессе сжигания топлива и при значительном рассеивании летучей золы и зольного остатка некоторые элементы могут накапливаться в окружающей среде.

\section{Заключение}

Содержание химических элементов в снежном покрове исследуемой территории значительно превышает их фоновые значения. Выявлены участки территории села Долонь с повешенным содержанием ряда тяжелых металлов, а именно мышьяка, кадмия, меди и свинца.

В ходе проведенных работ выявлено, что существенную часть загрязнения снежного покрова составляют труднорастворимые формы химических элементов. Данная форма химических элементов содержится в твердых частицах пылеаэрозольных выпадений. Также в фильтрате талого снега определена водорастворимая форма некоторых химических элементов - Cd, Ga, As и Sr. Содержание данных элементов в жидкой фазе снега составляет от 40 до $60 \%$ в сравнении с твердой фазой снега. Таким образом, в отопительный период для получения наиболее полной картины о состоянии воздушного бассейна необходимо изучение элементного состава твердой фазы снегового покрова. Данное исследование позволяет получить информацию о возможных источниках поступления химических элементов в атмосферу малых населенных пунктов, а также оценить качество воздуха исследуемой территории.

ность строительства и городского хозяйства. - 2019. - № 1. C. $29-35$.

10. Опыт использования снежного покрова в качестве универсального показателя загрязнения урбанизированных территорий / Д.В. Машкин, А.А. Гущин, Т.В. Извекова, Ю.Г. Боровова // Известия Иркутского государственного университета. Серия: Биология, Экология. - 2016. - Т. 18. - С. 58-73.

11. Филимонова Л.М., Паршин А.В., Бычинский В.А. Оценка загрязнения атмосферы в районе алюминиевого производства методом геохимической съемки снежного покрова // Метеорология и гидрология. - 2015. - № 10. - С. 75-84.

12. Fine particulate matter concentrations in urban Chinese cities, 2005-2016: a systematic review / M.Z. He, X. Zeng, K. Zhang, P.L. Kinney // International Journal of Environmental Research and Public Health. - 2017. - V. 14. - № 2. 191. DOI: 10.3390/ijerph14020191.

13. Personal and indoor PM2.5 exposure from burning solid fuels in vented and unvented stoves in a rural region of China with a high incidence of lung cancer / W. Hu, G.S. Downward, B. Reiss, J. Xu, B.A. Bassig, D. Hosgood, L. Zhang, W.J. Seow, G. Wu, R.S. Chapman, L. Tian, F. Wei, R. Vermeulen, Q. Lan // Environmental Science and Technology. - 2014. - V. 48. - № 15. P. 8456-8464. DOI: $10.1021 / \mathrm{es} 502201 \mathrm{~s}$

14. The level of air pollution in the impact zone of coal-fired power plant (Karaganda City) using the data of geochemical snow survey (Republic of Kazakhstan) / T.E. Adil'bayeva, A.V. Talovskaya, Ye.G. Yazikov, I.A. Matveenko // IOP Conference Series: Earth and Environmental Science. IOP Publishing. - 2016. - V. 43. № 1. - P. 1-5.

15. Characterization of outdoor air pollution from solid fuel combustion in Xuanwei and Fuyuan, a rural region of China / W. Hu, G.S. Downward, J.Y.Y. Wong, B. Reiss, N. Rothman, L. Portengen, J. Li, R.R. Jones, Y. Huang, K. Yang, Y. Chen, J. Xu, J. He, B. Bassig, W.J. Seow, H.D. Hosgood, L. Zhang, 
G. Wu, F. Wei, R. Vermeulen, Q. Lan // Scientific Reports. 2020. - V. 10. - № 1:11335. DOI: 10.1038/s41598-020-68229-2.

16. Characterization of solid airborne particles deposited in snow in the vicinity of urban fossil fuel thermal power plant (Western Siberia) / A.V. Talovskaya, E.G. Yazikov, E.A. Filimonenko, J.-C Lata, J. Kim, T.S. Shakhova // Environmental Technology (United Kingdom). - 2018. - V 39. - Iss. 18. - P. 2288-2303.

17. Identification of magnetic particulates in road dust accumulated on roadside snow using magnetic, geochemical and micromorphological analyses / M.S. Bucko, T. Magiera, B. Johanson, E. Petrovsky, L.J. Pesonen // Environmental Pollution. - 2011. V. 159 . - P. 1266-1276.

18. Пожитков Р.Ю., Московченко Д.В., Кудрявцев А.А. Геохимия снежного покрова г. Нижневартовска // Вестник Тюменского государственного университета. Экология и природопользование. - 2018. - Т. 4. - № 1. - С. 6-24.

19. Global sources of fine particulate matter: interpretation of PM2.5 chemical composition observed by SPARTAN using a global chemical transport model / C.L. Weagle, G. Snider, C. Li, A. van Donkelaar, S. Philip, P. Bissonnette, J. Burke, J. Jackson, R. Latimer, E. Stone, I. Abboud, C. Akoshile, N.X. Anh, J.R. Brook, A. Cohen, J. Dong, M.D. Gibson, D. Griffith, K.B. He, B.N. Holben, R. Kahn, Ch.A. Keller, J.S. Kim, N. Lagrosas, P. Lestari, Ye.L. Khian, Y. Liu, E.A. Marais, J.V. Martins, A. Misra, U. Muliane, R. Pratiwi, E.J. Quel, A. Salam, L. Segev, S.N. Tripathi, Ch. Wang, Q. Zhang, M. Brauer, Yi. Rudich, R.V. Martin // Environmental Science and Technology. - 2018. V. 52. - № 20. - P. 11670-11681. DOI: 10.1021/acs.est.8b01658

20. Individual particle SEM-EDS analysis of atmospheric aerosols in rural, urban, and industrial sites of Central Italy / A. Genga, T. Siciliano, M. Siciliano, D. Aiello, C. Tortorella // Environmental Monitoring and Assessment. - 2018. - V. 190. № 8. 456. DOI: 10.1007/s10661-018-6826-9.

21. Global chemical composition of ambient fine particulate matter for exposure assessment / S. Philip, R.V. Martin, A. van Donkelaar, J.W. Lo, Y. Wang, D. Chen, L. Zhang, P.S. Kasibhatla, S. Wang, Q. Zhang, Z. Lu, D.G. Streets, S. Bittman, D.J. Macdonald // Environmental Science and Technology. - 2014. - V. 48. № 22. - P. 13060-13068. DOI: 10.1021/es502965b

22. Лебедев А.Т. Масс-спектрометрия для анализа объектов окружающей среды. - М.: Техносфера, 2013. -632 c.

23. Геохимия окружающей среды / Ю.Е. Сает, Б.А. Ревич, Е.П. Янин, А.И. Ачкасов, И.Л. Башаркевич, Т.Л. Онищенко,
Л.Н. Павлова, С.Ш. Саркисян, Р.С. Смирнова, Н.Я. Трефилова. М.: Недра, 1990. -335 c.

24. Геохимия снежного покрова в восточном округе Москвы Н.С. Касимов, Н.Е. Кошелева, Д.В. Власов, Е.В. Терская // Вестник Московского университета. Серия 5. География. 2012. - № 4. - C. 14-24.

25. Многолетний мониторинг снежного покрова в условиях природных и урбанизированных ландшафтов Москвы и Подмосковья / Л.Г. Богатырев, Н.И. Жилин, В.П. Самсонова, Н.Л. Якушев, Н.П. Кириллова, А.И. Бенедиктова, Ф.И. Земсков, М.М. Карпухин, Д.В. Ладонин, А.Н. Вартанов, В.В. Демин // Вестник Московского Университета. Серия 5. География. - 2018. - № 2. - С. 85-96.

26. О составе снега на территории Верхнекамского солевого месторождения / С.М. Блинов, Е.А. Меньшикова, Е.Н. Батурин, Е.С. Ушакова, Л.Р. Золотарев // Лёд и Снег. - 2015. № 1 (129). - С. 121-128.

27. Холодова М.С., Пастухов М.В., Полетаева В.И. Особенности минерально-вещественного состава твердофазных выпадений снегового покрова территории г. Свирска // Известия Сибирского отделения Секции наук о Земле РАЕН. - 2016. № 4 (57). - С. 109-118.

28. Украинцев А.В., Плюснин А.М., Жамбалова Д.И. Использование химического состава снега для оценки долгосрочного влияния лесных пожаров на экологическое состояние территорий // Вестник ВГУ, Серия: География. Геоэкология. 2016. - № 2. - C. 56-62.

29. Оценка качества атмосферного воздуха сельских населенных пунктов и механизмов его формирования на примере с. Долонь / А.Е. Темиржанова, С.Н. Лукашенко, М.Т. Койгельдинова, Т.Г. Кириллова, А.Ж. Ташекова // Семипалатинский испытательный полигон. Радиационное наследие и перспективы развития: Тезисы докладов VII Международной научнопрактической конференции. - Павлодар: Дом печати, 2016. C. 92.

30. Экологическая характеристика атмосферных взвесей угольных объектов: от места добычи до сжигания / К.С. Голохваст, А.Н. Куприянов, Ю.А. Манаков, А.И. Агошков // Горный журнал. - 2017. - № 4. - С. 87-90.

31. Юдович Я.Э. Ценные элементы-примеси в углях. - Екатеринбург: УрО РАН, 2006. - 538 с.

Поступила 15.10.2020 2.

\section{Информация об авторах}

Teмиржанова A.E., инженер лаборатории элементного анализа Института радиационной безопасности и экологии Национального ядерного центра Республики Казахстан.

Дюсембаева M.T., PhD, начальник лаборатории элементного анализа Института радиационной безопасности и экологии Национального ядерного центра Республики Казахстан.

Лукашенко С.H., доктор биологических наук, главный научный сотрудник лаборатории радиохимии и аналитической химии Всероссийского научно-исследовательского института радиологии и агроэкологии.

Язиков $\boldsymbol{E}$.Г ., доктор геолого-минералогических наук, профессор отделения геологии Инженерной школы природных ресурсов Национального исследовательского Томского политехнического университета.

Шакенов E.3., инженер лаборатории элементного анализа Института радиационной безопасности и экологии Национального ядерного центра Республики Казахстан. 
UDC 574:504.3.054:541.182.2

\title{
ELEMENTAL COMPOSITION OF SNOW COVER SOLID PHASE IN SMALL SETTLEMENTS (THE CASE OF DOLON VILLAGE, REPUBLIC OF KAZAKHSTAN)
}

\author{
Aray E. Temirzhanova ${ }^{1}$, \\ temirzhanova.aray@mail.ru
}

\section{Madina T. Dyusembaeva ${ }^{1}$,} koigeldinova@nnc.kz

Sergey N. Lukashenko², lukashenko.1962@mail.ru

\section{Egor G. Yazikov³,}

yazikoveg@tpu.ru

Erbol Z. Shakenov'1,
shakenov@nnc.kz

1 National Nuclear Center of the Republic of Kazakhstan,

2, Beibit Atom street, Kurchatov, 071100, Kazakhstan.

2 All-Russian Research Institute of Radiology and Agroecology, 109 km, Kiev highway, Obninsk, 249032, Russia.

${ }^{3}$ National Research Tomsk Polytechnic University, 30, Lenin avenue, Tomsk, 634050, Russia.

The relevance of this work is caused by the need to expand the methods of complex environmental studies to assess the quality of environmental objects in small communities. The study of the elemental composition of dust and aerosol depositions will provide the most complete picture of the quality status of the main natural components. Air aerosols are a complex dispersed system that includes particles smaller than 10 microns. These particles have both natural and man-made origin: finely dispersed dust particles of soil, plants, microorganisms, soot, ash, components of smoke emissions from boiler houses, industry, etc. Atmospheric air of small settlements remains poorly studied, there are no systematic data on the chemical composition of atmospheric pollutants, and therefore the relevance of this work is determined.

The aim of the research is to determine the elemental composition of the solid phase of the snow cover of a small settlement Dolon.

Objects: dust-aerosol deposition, particulate matter of air aerosols, snow cover, coal and ash.

Techniques: mass spectrometric and atomic emission with inductively coupled plasma (MS-ISP, OES-ISP)

Results. The elemental composition of snow melt water and solid phase of snow was studied. To determine the degree of volatility of chemical elements their coefficient of enrichment from coal to ash was calculated. The main zones with increased content of heavy metals in dust and aerosol depositions were determined. In the snow cover of the investigated territory a group of elements with high migratory capacity was revealed. Maps of the snow cover pollution of the Dolon settlement were constructed with identification of areas (halos of pollution) with increased content of the studied groups of elements.

\section{Key words:}

Dust-aerosol deposition, snow cover, solid snow residue, meltwater, dust loading, heavy metals.

\section{REFERENCES}

1. Carmagnola C.M., Domine F., Dumont M., Wright P., Strellis B., Bergin M., Dibb J., Picard G., Libois Q., Arnaud L., Morin S. Snow spectral albedo at Summit, Greenland: measurements and numerical simulations based on physical and chemical properties of the snowpack. The Cryosphere, 2013, vol. 7, no. 4, pp. 1139-1160.

2. McNeill V.F. Atmospheric aerosols: clouds, chemistry, and climate. Annual review chemical and biomolecular engineering, 2017, vol. 8, pp. 427-444. DOI: 10.1146/annurev-chembioeng060816-101538

3. Kholodov A.S. Geoekologicheskaya otsenka zagryazneniya atmosfery malykh $i$ srednikh naselennykh punktov Primorskogo kraya mikrorazmernymi chasti. Dis. Kand. nauk [Geoecological assessment of the atmosphere pollution of small and medium-sized settlements of the Primorsky Krai by micro-dimensional particles. Cand. Diss.]. Vladivostok, 2019. 184 p.

4. Andreyeva I.S., Ankilov A.N., Baklanov A.M., Kutsenogiy K.P. Aerozoli Sibiri [Siberian aerosols]. Novosibirsk, SO RAN Publ., 2006. $548 \mathrm{p}$.
5. Mołocznik A. Qualitative and quantitative analysis of agricultural dust in working environment. Annals of agricultural environmental medicine, 2002, vol. 9, no. 1, pp. 71-78.

6. Wang Y., Ying Q., Hu J., Zhang H. Spatial and temporal variations of six criteria air pollutants in 31 provincial capital cities in China during 2013-2014. Environment international, 2014, vol. 73, pp. 413-422. DOI: 10.1016/j.envint.2014.08.016

7. Elik A. Monitoring of heavy metals in urban snow as indicator of atmosphere pollution. International Journal of Environmental Analytical Chemistry, 2002, vol. 82, no. 1, pp. 37-45.

8. Kirillin A.R, Makarov V.N. Geochemistry of snow cover of mountain permafrost landscapes within the Elkon uranium ore district. Science and education, 2016, no. 4, pp. 64-69. In Rus.

9. Nesterov E.M., Zarina L.M., Markova M.A., Gracheva I.V., Vorontsova A.V., Makarova Yu.A. Study of ecological condition of the snow cover of St. Petersburg. Ecological safety of construction and urban economy, 2019, no. 1, pp. 29-35. In Rus. DOI: 10.24411/1816-1863-2019-11029

10. Mashkin D.V., Guschin A.A., Izvekova T.V., Borovova Yu.G. Experience in the use of snow cover as a universal indicator of 
pollution in urban areas. Izvestia Irkutsk State University. Series: Biology, Ecology, 2016, vol. 18, pp. 58-73. In Rus.

11. Filimonova L.M., Bychinskii V.A., Parshin A.V. Air pollution assessment in the area of aluminum production by snow geochemical survey. Russian Meteorology and Hydrology, 2015, no. 10 , pp. $75-84$. In Rus.

12. He M.Z., Zeng X., Zhang K., Kinney P.L. Fine particulate matter concentrations in urban Chinese cities, 2005-2016: a systematic review. International Journal of Environmental Research and Public Health, 2017, vol. 14, no. 2. 191. DOI: 10.3390/ijerph14020191.

13. Hu W., Downward G.S., Reiss B., B.A. Bassig, J. Xu, Hosgood D. Zhang L., Seow W.J., Wu G., Chapman R.S., Tian L., Wei F., Vermeulen R., Lan Q. Personal and indoor PM2.5 exposure from burning solid fuels in vented and unvented stoves in a rural region of China with a high incidence of lung cancer. Environmental Science and Technology, 2014, vol. 48, no. 15, pp. 8456-8464. DOI: 10.1021/es502201s

14. Adil'Bayeva T.E., Talovskaya A.V., Yazikov Ye.G., Matveenko I.A. The level of air pollution in the impact zone of coal-fired power plant (Karaganda City) using the data of geochemical snow survey (Republic of Kazakhstan). IOP Conference Series: Earth and Environmental Science. IOP Publishing, 2016, vol. 43, no. 1, pp. 1-5.

15. Hu W., Downward G.S., Wong J.Y.Y., Reiss B., Rothman N., Portengen L., Li J., Jones R.R., Huang Y., Yang K., Chen Y., Xu J., He J., Bassig B., Seow W.J., Hosgood H.D., Zhang L., Wu G., Wei F., Vermeulen R., Lan Q. Characterization of outdoor air pollution from solid fuel combustion in Xuanwei and Fuyuan, a rural region of China. Scientific Reports, 2020, vol. 10, no. 1:11335. DOI: 10.1038/s41598-020-68229-2.

16. Talovskaya A.V., Yazikov E.G., Filimonenko E.A., Lata J.-C, Kim J., Shakhova T.S. Characterization of solid airborne particles deposited in snow in the vicinity of urban fossil fuel thermal power plant (Western Siberia). Environmental Technology (United Kingdom), 2018, vol. 39, no. 18, pp. 2288-2303.

17. Bucko M.S., Magiera T., Johanson B., Petrovsky E., Pesonen L.J. Identification of magnetic particulates in road dust accumulated on roadside snow using magnetic, geochemical and micromorphological analyses. Environmental Pollution, 2011, vol. 159, pp. 1266-1276.

18. Pozhitkov R.Yu, Moskovchenko D., Kudryavtsev A.A. The geochemistry of snow cover in Nizhnevartovsk. Tyumen State University Herald. Natural Resource Use and Ecology, 2018 vol. 4, no. 1, pp. 6-24. In Rus. DOI: 10.21684/2411-7927-2018-4$1-6-24$

19. Weagle C.L., Snider G., Li C., Van Donkelaar A., Philip S., Bissonnette P., Burke J., Jackson J., Latimer R., Stone E., Abboud I., Akoshile C., Anh N.X., Brook J.R., Cohen A., Dong J., Gibson M.D., Griffith D., He K.B., Holben B.N., Kahn R., Keller Ch.A., Kim J.S., Lagrosas N., Lestari P., Khian Ye.L., Liu Y., Marais E.A., Martins J.V., Misra A., Muliane U., Pratiwi R., Quel E.J., Salam A., Segev L., Tripathi S.N., Wang Ch., Zhang Q., Brauer M., Rudich Yi., Martin R.V. Global sources of fine particulate matter: interpretation of PM2.5 chemical composition observed by SPARTAN using a global chemical transport model. Environmental Science and Technology, 2018, vol. 52, no. 20, pp. 11670-11681. DOI: 10.1021/acs.est.8b01658

20. Genga A., Siciliano T., Siciliano M., Aiello D., Tortorella C. Individual particle SEM-EDS analysis of atmospheric aerosols in rural, urban, and industrial sites of Central Italy. Environmental
Monitoring and Assessment, 2018, vol. 190, no. 8. 456. DOI: 10.1007/s10661-018-6826-9.

21. Philip S., Martin R.V., van Donkelaar A., Lo J. W., Wang Y., Chen D., Zhang L., Kasibhatla P.S., Wang S., Zhang Q., Lu Z., Streets D.G., Bittman S., Macdonald D.J. Global chemical composition of ambient fine particulate matter for exposure assessment, Environmental Science and Technology, 2014, vol. 48, no. 22, pp. 13060-13068. DOI: 10.1021/es502965b

22. Lebedev A.T. Mass-spektrometriya dlya analiza obyektov okruzhayushchey sredy [Mass spectrometry for environmental object analysis]. Moscow, Tekhnosfera Publ., 2013. 632 p.

23. Sayet Yu.E., Revich B.A., Yanin E.P., Achkasov A.I., Basharkevich I.L., Onishchenko T.L., Pavlova L.N., Sarkisyan S.Sh., Smirnova R.S., Trefilova N.Ya. Geokhimiya okruzhayushchey sredy [Environmental geochemistry]. Moscow, Nedra Publ., 1990. 335 p.

24. Kasimov N.S., Kosheleva N.E., Vlasov D.V., Terskaya E.V. Geochemistry of snow cover within the eastern district of Moscow. Herald of Moscow University. Series 5. Geography, 2012, no. 4, pp. 14-24. In Rus.

25. Bogatyrev L.G., Zhilin N.I., Samsonova V.P., Yakushev N.L., Kirillova N.P., Benediktova A.I., Zemskov Ph.I., Karpuhin M.M., Ladonin D.V., Vartanov A.N., Demin V.V. Long-term monitoring of snow cover within natural and urbanized landscapes of the Moscow region. Herald of Moscow University. Series 5. Geography, 2018, no. 2, pp. 85-96. In Rus.

26. Blinov S.M., Menshikova E.A., Baturin E.N., Ushakova E.S., Zolotarev L.R. On a snow cover composition in the vicinity of the Verkhnekamsky Salt Deposit. Ice and snow, 2015, vol. 1, no. 129, pp. 121-128 In Rus. DOI: 10.15356/IS.2015.01.10

27. Kholodova M.S., Pastukhov M.V., Poletaeva V.I. Features of mineral and material composition of snow cover solid-phase precipitations in the town of Svirsk area. Proceedings of the Siberian Department of the Section of Earth Sciences, Russian Academy of Natural Sciences. Geology, Prospecting and Exploration of Ore Deposits, 2016, vol. 4, no. 57, pp. 109-118. DOI: 10.21285/0130-108X-2016-57-4-109-118.

28. Ukraintsev A.V., Plyusnin A.M., Zhambalova D.I. Use of the snow chemical composition for estimation of the long-term influence of the forest fires on the ecological state of the territories (in Russian). Bulletin of Voronezh State University, Series: Geography. Geo-ecology, 2016, no. 2, pp. 56-62. In Rus.

29. Temirzhanova A.E., Lukashenko S.N., Koygeldinova M.T., Kirillova T.G., Tashekova A.Zh. Otsenka kachestva atmosfernogo vozdukha naselennykh punktov i mekhanizmov ego formirovaniya na primere s. Dolon [Assessment of the atmospheric air quality in settlements and mechanisms of its formation on the example of Dolon village]. Tezisy dokladov VII Mezhdunarodnoy nauchnoprakticheskoy konferentsii. Semipalatinskiy ispytatelny poligon. Radiatsionnoe nasledie i perspektivy razvitiva [Theses of reports of the VII International Scientific and Practical Conference. Semipalatinsk Test Site. Radiation heritage and development prospects]. Pavlodar, Dom pechati Publ., 2016. p. 92.

30. Golokhvast K.S., Kupriyanov A.N., Manakov Yu.A., Agoshkov A.I. Ecological characteristics of the atmospheric weights of the coal objects: from a mining place to burning. Mining magazine, 2017, no. 4, pp. 87-90. In Rus.

31. Yudovich Ya.E., Ketris M.P. Tsennyye elementy-primesi v uglyakh [Valuable trace elements in coal]. Ekaterinburg, UrO RAN, 2006. $538 \mathrm{p}$.

Received: 15 October 2020.

\section{Information about the authors}

Aray E. Temirzhanova, engineer, National Nuclear Center of the Republic of Kazakhstan.

Madina T. Dyusembaeva, PhD, head of Elemental Analysis Laboratory, National Nuclear Center of the Republic of Kazakhstan.

Sergey N. Lukashenko, Dr. Sc., chief researcher, All-Russian Research Institute of Radiology and Agroecology.

Egor G. Yazikov, Dr. Sc., professor, National Research Tomsk Polytechnic University.

Erbol Z. Shakenov, engineer, National Nuclear Center of the Republic of Kazakhstan. 